\title{
Numerical Study on Internal flow Field Dynamic Performance of Scramjet
}

\author{
Feng Gao*, Jie Zhao, Feng Li Chen \\ Air and Missile Defense College, Air Force Engineering University, 710051 Shaanxi Xian, China
}

\begin{abstract}
The pressure pulsation caused by the combustion of the combustion chamber of the scramjet engine has a great influence on the flow and performance of the inlet. Although the isolation section prevents the propagation of this pressure pulsation, the pressure pulsation still flows to the inlet flow field. And performance has an adverse effect. In this paper, a method for calculating the dynamic performance parameters of the inlet is discussed. The influence of the pulsating pressure of the combustion chamber on the performance of the inlet is preliminarily studied. The influence law of different forms of back pressure pulsation on the flow coefficient and the total pressure recovery coefficient is obtained. Different back pressure pulsation forms have a great influence on the flow coefficient. The faster the response, the more obvious the change of the flow coefficient. The larger the reduction, the more likely the inlet channel will not start. Different back pressure pulsations have little effect on the total pressure recovery coefficient. In the design of the intake port, the influence of the back pressure pulsation on the performance of the intake port should be fully taken into consideration, and measures should be taken to prevent the performance of the intake port from being affected by the back pressure pulsation.
\end{abstract}

\section{Introduction}

The structure of the hypersonic vehicle, the scramjet and the intake port is shown in Figure 1. The inlet of the scramjet engine is the intake device of the scramjet engine, and its performance is directly related to whether the scramjet engine can work normally and its performance is good or bad. Researchers at home and abroad have conducted a lot of research on this and have achieved fruitful work $[1,2,3,4,5,6]$. During the operation of the scramjet engine, the pressure pulsation caused by the combustion of the combustion chamber has a great influence on the airflow of the intake port[7, 8]. Although the isolation section prevents the propagation of such pressure pulsation, the pressure pulsation is still correct. The flow and performance of the airway flow field have an adverse effect. This paper explores a calculation method to simulate the influence of combustion chamber pressure pulsation on the performance of the inlet. Although there is a certain difference between the actual combustion pressure and the pulsation on the inlet, it can be approximated to simulate its trend. Research lays the foundation.

\section{COMPUTATIONAL METHODOLOGY}

\subsection{Computational Model and Method}

The supersonic combustor considered in the present study uses the binary air-inlets model in paper, the geometry structures and parameters as shown in the Fig. 2. and Table 1. [9]. The calculated flow conditions are: the incoming Mach number $\mathrm{Ma}=6$, the total pressure $P_{\mathrm{t}}=4137551.21 \mathrm{~Pa}$, and the total temperature $T_{\mathrm{t}}=1718.6 \mathrm{~K}$.

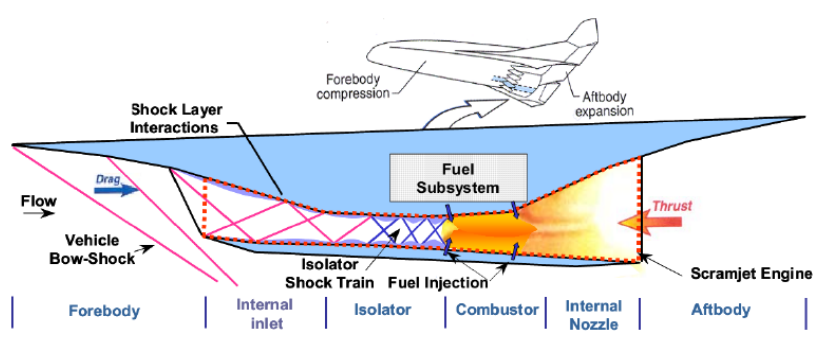

Fig. 1. Schematic diagram of scramjet engine structure

\footnotetext{
* Corresponding author: gnning@sina.com
} 


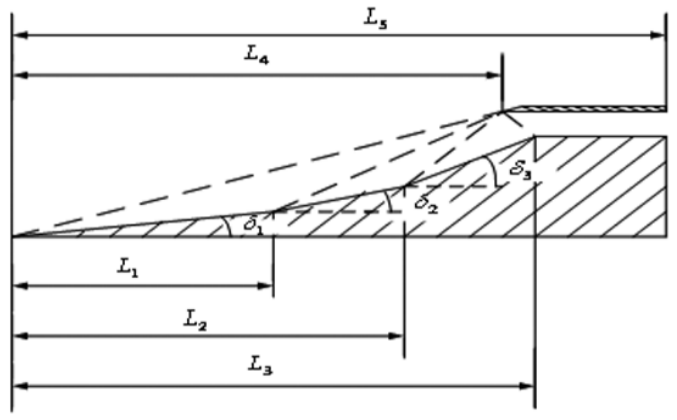

Fig. 2. The sketch of the binary air-inlets/ the separation of the isolation period model

Table 1. The size of the binary air-inlets/ the separation of the isolation period model

\begin{tabular}{|c|c|c|c|c|c|c|c|c|}
\hline$\delta_{1}\left({ }^{\mathbf{o}}\right)$ & $\delta_{2}\left(^{(\mathbf{o}}\right)$ & $\delta_{3}\left({ }^{\mathbf{o}}\right)$ & $\begin{array}{c}L_{1} \\
(\mathrm{~mm})\end{array}$ & $\begin{array}{c}L_{2} \\
(\mathrm{~mm})\end{array}$ & $\begin{array}{c}L_{3} \\
(\mathrm{~mm})\end{array}$ & $\begin{array}{c}L_{4} \\
(\mathrm{~mm})\end{array}$ & $\begin{array}{c}L_{5} \\
(\mathrm{~mm})\end{array}$ & $\begin{array}{c}h_{t h} \\
(\mathrm{~mm})\end{array}$ \\
\hline 6.0 & 6.78 & 7.70 & 628.92 & 925.17 & 1295.42 & 1200 & 1655.42 & 30 \\
\hline
\end{tabular}

\subsection{Approaching method of air-inlet parameters}

The air-inlet parameters are composed of total pressure recovering coefficient, flow rate coefficient, additional resistance coefficient and ram ratio. This paper mainly uses total pressure recovering coefficient and flow rate coefficient to evaluate the performance of the scramjet air-inlet.

(1) Total pressure recovering coefficient is defined as ratio between inlet average total pressure and outlet average total pressure which is to assess the airflow kinetic energy loss in the process of stagnation. Equation for this is given by Eq. (1)

$$
\sigma=\frac{P_{t e}}{P_{t 0}}
$$

(2) Flow rate coefficient ratio, ratio between actual inlet flow rate coefficient and inlet free flow rate coefficient without being disturbance. Equation for this is given by Eq. (2)

$$
\varphi=\frac{A_{0}}{A_{c}}
$$

\subsection{Geometry design and Numerical approach}

A refined grid was developed with Gambit to simulate the air-inlet section geometry for the CFD solver. On account of the complicacy of the air-inlet structure, the whole area is separated into eight parts. In consideration of the influence of layer boundary, increasing the boundary layer mesh is necessary. As shown in Figure 3. As is shown in figure 2, a-b-c is designated as pressure inlet, c-d-e-f-g is designated as pressure-far-fields, $\mathrm{g}$ - $\mathrm{h}$ is designated as pressure-outlet, a-m-l-k-j, i-n and n-o-h are designated as wall boundaries, and $\mathrm{i}-\mathrm{j}$ is defined as unsteady Back-pressure dynamic fluctuation boundary conditions through UDF.

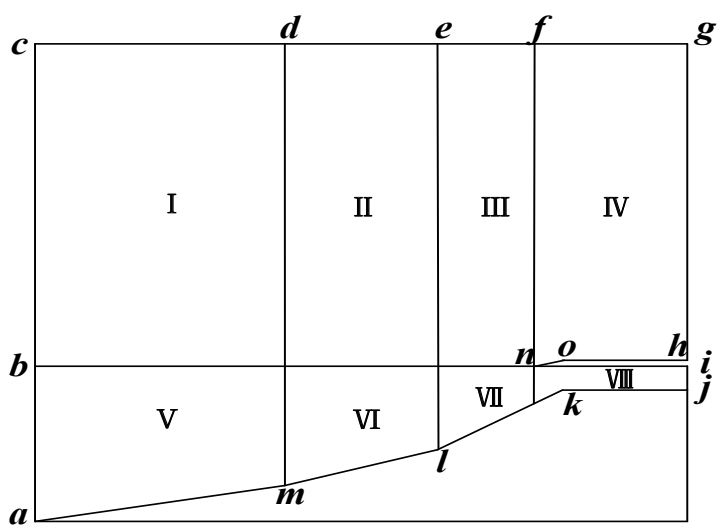

Figure 3. Geometry of air-inlet and boundary calibration 


\subsection{Computational Methodology}

In addition to the compressible Navier-Stokes and energy equations, the K-epsilon Turbulence model is utilized in this paper. In near wall region nonequilibrium wall function method is adopted. In order to catch the shock wave, double-precision equation solver and implicit coupling method are applied. Second Order Upwind was selected in discretization scheme.

$$
\int_{\Omega} \frac{\partial Q}{\partial t} d \Omega+\oint_{\Gamma}(\vec{F}-\vec{G}) \cdot d S=0
$$

\subsection{Initial conditions and Convergence criteria}

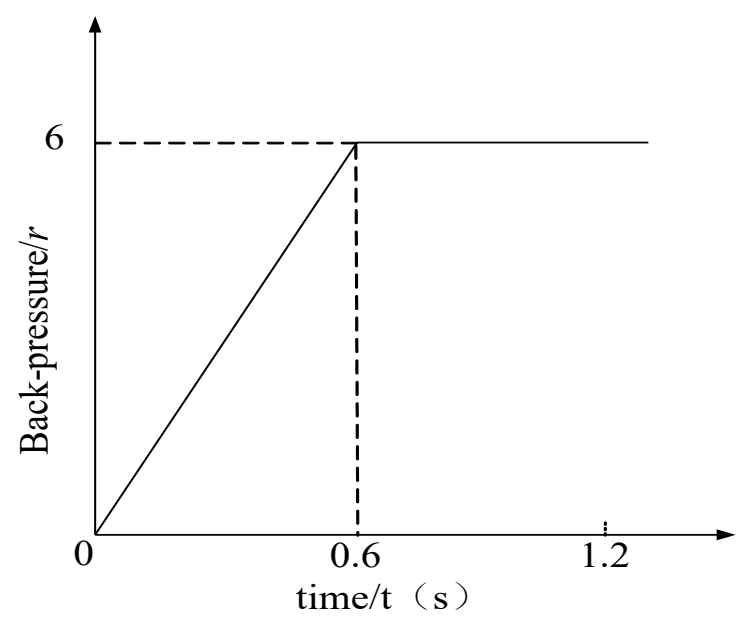

(a) Pulsation form a
First, initialize the flow field with the calculation result of steady-state. The shock wave increases residuals, so when every parameter's residual is below $10^{-3}$ and keeping steady, criterion for convergence is met.

\section{RESULTS AND DISCUSSION}

Internal and External flow field in air-inlet were simulated on different back-pressure conditions at the combustor entrance corresponds to Mach 6 scramjet flights. To find out how the pressure fluctuation of the scramjet combustor influents the flow and performance of the scramjet inlet, UDF part in Fluent was applied to simulate two different back-pressure fluctuations in the same amplitude but different responses which is shown in figure4.

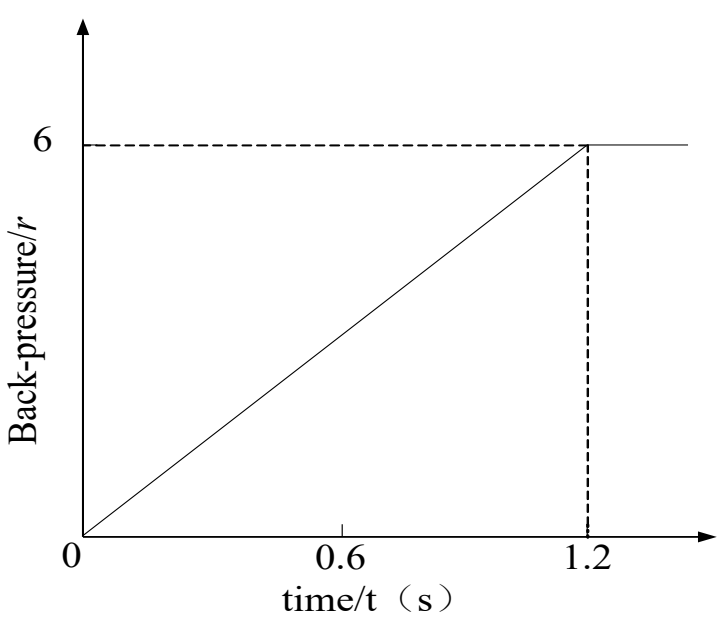

(b) Pulsation form $b$

Fig. 4. Simulating back-pressure pulsation form in combustor

Figure 5 shows the nature changeability in flow rate coefficient as time increases for two pulsating forms. Figure 6 shows the nature changeability in total pressure recovering rate as time increases for two pulsating forms. From the whole tendency of the curves, the flow rate coefficient and the total pressure recovering rate reduce as time increases while fluctuating in the middle of the cures. Back-pressure pulsation has great effects on the flow rate coefficient but has little effect on total pressure recovering rate. In the pulsating form a, the flow coefficient is 0.15 , and in the pulsating form $b$, the flow coefficient is 0.45 . Different back pressure pulsations have little effect on the total pressure recovery coefficient. The total pressure recovery coefficient of the two pulsating forms remains basically unchanged at around 0.27. Comparing $\mathrm{a}$ with $\mathrm{b}$ in figure 5, the responding faster the more obvious the changeability of flow rate coefficient. It may cause the air-inlet flaming out when the back-pressure is too low. Figure 6 shows that the total pressure recovering rates for different airinlets are similar with each other in different backpressure pulsation forms. So, it is necessary to take the influence of back-pressure pulsation which is caused by ignition into consideration when designing air-inlet in major engineering design projects. 


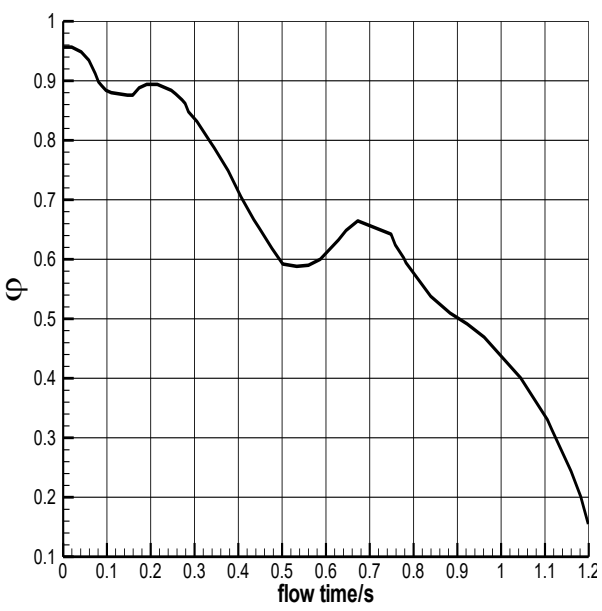

(a) Pulsation form a

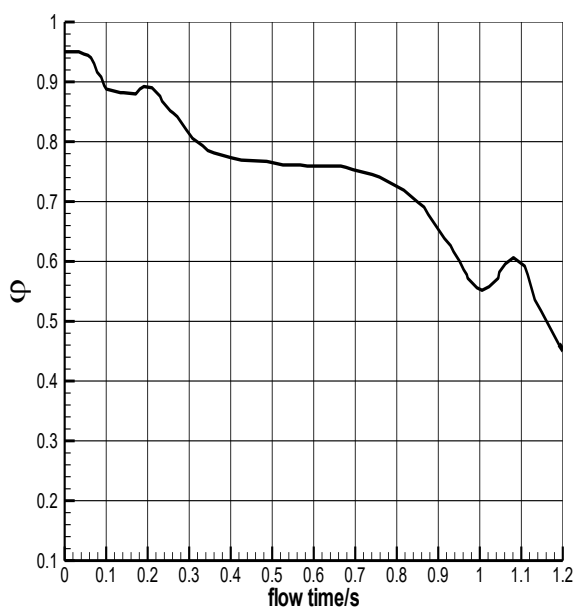

(b) Pulsation form $b$

Fig. 5. Air-inlet flow rate coefficient as time increases

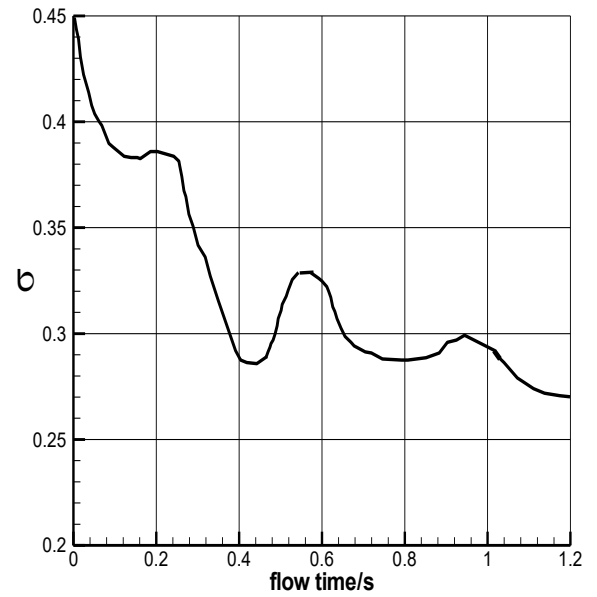

(a) Pulsation form a

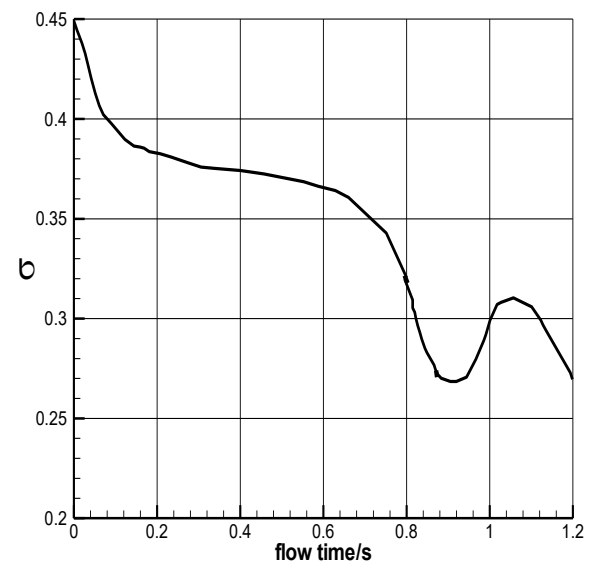

(b) Pulsation form

Fig. 6. Air-inlet total pressure recovering rate coefficient as time increases

\section{Summary and Conclusions}

In this paper, the influence of the pressure fluctuation of the scramjet combustor on the flow and performance of the scramjet inlet were studied, conclusions are as follows:

(1)Back-pressure pulsation has great effects on the flow rate coefficient but has little effect on total pressure recovering rate. Comparing a with $\mathrm{b}$ in figure 4 , the responding faster the more obvious the changeability of flow rate coefficient. It may cause the air-inlet flaming out when the back-pressure is too low.
(2) Back-pressure pulsation has little effect on total pressure recovering rate.

(3) It is necessary to take the influence of backpressure pulsation into consideration and take measures to prevent substantial fluctuation performance of the scramjet inlet when designing air-inlet in major engineering design projects.

\section{References}

1. Mary Kae L. O'Neill and Mark J. Lewis, Journal of Aircraft, 29, 6 (1992) 
2. Logan P. Riley, Datta V. Gaitonde, Mark A. Hagenmaier, Jeffrey M. Donbar, Journal of Propulsion and Power, 34, 6 (2018)

3. Michael K. Smart, AIAA Journal, 50, 3 (2012)

4. D. V. Gaitonde; M. R. Visbal; J. S. Shang; A. A. Zheltovodov; A. I. Maksimov, Journal of Propulsion and Power, 17, 3 (2001)

5. Hideaki Ogawa, Russell R. Boyce, AIAA Journal, 50, 8 (2012)
6. Qili Liu, Andrea Passaro, Damiano Baccarella, Hyungrok Do, Journal of Propulsion and Power, 30, 6 (2014)

7. Jinhu Feng, Feng Gao, Journal of Air Force Engineering University(Natural Science Edition), 10, 4(2009)

8. Feng Gao, Hongyu Wang, Winged Missiles Journal, 1: $80 \sim 84(2014)$

9. Zhilin He, Feng Gao, Winged Missiles Journal, 4: $82 \sim 87$ (2010) 